Toshiharu Kasaba MD,

Osamu Kondou MD,

Yasuhiro Yoshimura MD,

Yumi Watanabe MD,

Mayumi Takasaki MD

\title{
Haemodynamic effects of induction of general anaesthesia with propo- fol during epidural anaesthesia
}

Purpose: To clarify whether propofol administration during thoracic or lumbar epidural anaesthesia intensifies the haemodynamic depression associated with epidural anaesthesia.

Methods: Patients $(n=45)$ undergoing procedures of similar magnitude were randomly divided into three study groups: a control group $(n=15)$ receiving general anaesthesia alone and two study groups undergoing thoracic $(n=15)$ and lumbar epidural anaesthesia $(n=15)$ before induction of general anaesthesia. All patients received $2 \mathrm{mg} \cdot \mathrm{kg}^{-1}$ propofol at a rate of $200 \mathrm{mg} \cdot \mathrm{min}^{-1}$, followed by a continuous infusion of $4 \mathrm{mg} \cdot \mathrm{kg}^{-1} \cdot \mathrm{hr}^{-1}$. Mean arterial blood pressure (MAP) and heart rate (HR) were measured at baseline, three minutes after induction, and one minute after tracheal intubation in all three groups and at 20 min after epidural anaesthesia was established in the thoracic and lumbar groups.

Results: Following epidural anaesthesia, MAP decreased from $94 \pm 14(\mathrm{SD})$ at baseline to $75 \pm 11 \mathrm{mmHg}(P$ $<0.0001$ ) in the thoracic group and from $92 \pm 12$ to $83 \pm 15 \mathrm{mmHg}$ in the lumbar group. After propofol administration, MAP decreased further in the thoracic group to $63 \pm 9 \mathrm{mmHg}(P=0.0077)$ and to $67 \pm 10$ $\mathrm{mmHg}(P=0.0076)$ in the lumbar group. The MAP following propofol induction in the thoracic group $(P<$ $0.0001)$ and in the lumbar group $(P=0.0001)$ was lower than MAP in the control group $(81 \pm 9 \mathrm{mmHg})$. HR decreased only in response to thoracic epidural anaesthesia $(P=0.0066)$.

Conclusion: The hypotensive effects of propofol are additive to those of epidural anaesthesia, resulting in a profound decrease in mean arterial pressure.

Objectif : Déterminer si l'administration de propofol pendant une anesthésie péridurale thoracique ou lombaire intensifie la dépression hémodynamique associée à l'anesthésie péridurale.

Méthode : Des patients $(n=45)$ devant subir des interventions d'importance similaire ont été répartis au hasard en trois groupes : un groupe témoin $(n=15)$ qui a reçu seulement une anesthésie générale et deux groupes d'étude devant subir une anesthésie péridurale thoracique $(n=15)$ et lombaire $(n=15)$ avant l'induction de l'anesthésie générale. Tous les patients ont reçu $2 \mathrm{mg} \cdot \mathrm{kg}^{-1}$ de propofol à $200 \mathrm{mg} \cdot \mathrm{min}^{-1}$, suivi d'une perfusion continue de $4 \mathrm{mg} \cdot \mathrm{kg}^{-1} \cdot \mathrm{hr}^{-1}$. La tension artérielle moyenne (TAM) et la fréquence cardiaque (FC) ont fait l'objet de mesures de base, trois minutes après l'induction, et une minute après l'intubation endotrachéale chez tous les patients, de même que 20 min après que l'anesthésie péridurale thoracique et lombaire a été établie dans les deux groupes concernés.

Résultats : À la suite de l'anesthésie péridurale, la TAM de base a diminué pour passer de $94 \pm 14$ (SD) à 75 $\pm 11 \mathrm{mmHg}(P<0,000 \mathrm{I})$ chez les patients du groupe d'anesthésie thoracique, et de $92 \pm 12 \mathrm{à} 83 \pm 15 \mathrm{mmHg}$ chez les patients qui ont reçu l'anesthésie lombaire. Après l'administration de propofol, la TAM a diminué encore à $63 \pm 9 \mathrm{mmHg}$ dans le groupe thoracique $(P=0,0077)$ et à $67 \pm 10 \mathrm{mmHg}(P=0,0076)$ dans le groupe lombaire. La TAM, à la suite de l'induction au propofol, était plus basse dans les deux groupes d'étude thoracique $(P<0,0001)$ et lombaire $(P=0,0001$ que la TAM du groupe témoin $(81 \pm 9 \mathrm{mmHg})$. La FC a diminué seulement en réaction à l'anesthésie péridurale thoracique $(P=0,0066)$.

Conclusion : Les effets hypotenseurs du propofol s'ajoutent à ceux de l'anesthésie péridurale, ce qui a comme résultat de diminuer la tension artérielle moyenne de façon importante.

From the Department of Anesthesiology, Miyazaki Medical College, Kiyotake-Cho, Miyazaki, 889-16, Japan.

Address all correspondence to: Dr. T. Kasaba, Phone: 81-985-85-2970; Fax: 81-985-85-7179; E-mail: binjik@postl.miyazaki-med.ac.jp Accepted for publication August 28, 1998 
A $\mathrm{N}$ anaesthetic technique combining epidural with light general anaesthesia for upper and lower abdominal surgery is well-known. However, if propofol is administered for the induction of general anaesthesia, then the combined haemodynamic effects of this agent and the epidural technique may be considerable. Both the epidural anaesthesia ${ }^{1}$ and propofol $^{2}$ decrease sympathetic nerve activity, producing marked hypotension; propofol also reduces vascular smooth muscle tone and cardiac contractility. ${ }^{3-5}$

Data regarding the haemodynamic effects of propofol during epidural anaesthesia are contradictory. Several studies report that administration of $<0.7$ $\mathrm{mg} \cdot \mathrm{kg}^{-1}$ or by continuous infusion of $3.6-4.0$ $\mathrm{mg} \cdot \mathrm{kg}^{-1} \cdot \mathrm{hr}^{-1}$ during epidural anaesthesia has no effect on blood pressure, ${ }^{6,7}$ while others indicate a reduction in blood pressure with $1.5 \mathrm{mg} \cdot \mathrm{kg}^{-1}$ and continuous infusion of $1.5-3.0 \mathrm{mg} \cdot \mathrm{kg}^{-1} \cdot \mathrm{hr}^{-1}$. 8 Similarly, two studies of approximately the same induction (2.0 vs 2.1 $\left.\mathrm{mg} \cdot \mathrm{kg}^{-1}\right)$ and infusion doses $\left(6-7.8 \mathrm{vs} 6.2 \mathrm{mg} \cdot \mathrm{kg}^{-1} \cdot \mathrm{hr}^{-1}\right)$ reported opposite effects on systolic and diastolic blood pressures. ${ }^{910}$ Common to all these investigations is that none separates the haemodynamic effects of propofol from those of epidural anaesthesia.

In the present study, we distinguished the hypotensive effects of propofol and of epidural anaesthesia, and determined whether these effects war additive. Specifically, we investigated whether propofol administration during thoracic or lumbar epidural anaesthesia exacerbated the haemodynamic depression associated with epidural anaesthesia.

\section{Methods}

With approval from our Human Research Review Committee and informed consent, 45 patients, ASA classification I or II were studied. Exclusion criteria included hypertension, diabetes or contraindications to epidural anaesthesia. Patients were randomly divided into three groups of 15: a control group who received general anaesthesia alone to undergo thyroidectomy or tympanoplasty; a thoracic group given thoracic epidural anaesthesia before general anaesthesia for lobectomy or mastectomy; and, a lumbar group given lumbar epidural anaesthesia before general anaesthesia for gastrectomy or hysterectomy. All patients received premedication with $0.5 \mathrm{mg}$ atropine and $25 \mathrm{mg}$ hydroxyzine $i m$ one hour before induction of anaesthesia.

\section{Epidural technique}

Patients in the thoracic and lumbar epidural groups received $500 \mathrm{~mL}$ hydroxyethyl starch (HES) solution intravenously at a rate of $15 \mathrm{~mL} \cdot \mathrm{kg}^{-1} \cdot \mathrm{hr}^{-1}$ for volume loading beginning $20 \mathrm{~min}$ before epidural anaesthesia. This was followed by administration of acetated Ringer's solution. With patients in the lateral decubitus position, infiltration of 3-5 mL lidocaine $1 \%$ for local anaesthesia allowed us to identify the epidural space by loss of resistance to saline injection using a 17-gauge Tuohy needle at the $\mathrm{T}_{5.6}$ or $\mathrm{T}_{6.7}$ interspace in the thoracic group and at $\mathrm{L}_{1-2}$ or $\mathrm{L}_{2-3}$ in the lumbar group. An epidural catheter was then inserted $3 \mathrm{~cm}$ cephalad and the patient was turned supine. A volume of $10 \mathrm{~mL}$ mepivacaine $2 \%$ was injected epidurally over one minute. Twenty minutes after epidural injection, the spread of analgesia was determined by response to pin-prick.

\section{Induction of general anaesthesia with propofol}

General anaesthesia was induced in all groups with 2 $\mathrm{mg} \cdot \mathrm{kg}^{-1}$ propofol, at a rate of $200 \mathrm{mg} \cdot \mathrm{min}^{-1}$, followed by a continuous infusion of $4 \mathrm{mg} \cdot \mathrm{kg}^{-1} \cdot \mathrm{hr}^{-1}$ via a constant infusion pump (STC-525X, Terumo, Tokyo, Japan). Vecuronium, $0.15 \mathrm{mg} \cdot \mathrm{kg}^{-1}$ iv was administered after the bolus injection of propofol and the trachea was intubated three minutes after.

\section{Measurements}

Arterial blood pressure was measured with an oscillometer using a cuff, and mean arterial blood pressure (MAP) was calculated electronically (BSM-8500, Nihon-Koden, Tokyo, Japan). Heart rate (HR) was determined electrocardiographically (BSM-8500, Nihon-Koden, Tokyo, Japan). In all study groups, MAP and HR were measured at baseline, three minutes after propofol induction, and one minute after tracheal intubation. In the thoracic and lumbar epidural groups, MAP and HR also were measured at $20 \mathrm{~min}$ after epidural anaesthesia was established. In all patients, a reduction in MAP $<50 \mathrm{mmHg}$ was treated with $10 \mathrm{mg}$ ephedrine $i v$. Once measurements were obtained, the conduct of anaesthesia was left to the discretion of the attending anaesthetist. Anaesthesia was maintained with epidural block and a low concentration of sevoflurane (1.0\%) or isoflurane $(0.8 \%)$ in the thoracic and lumbar epidural groups, and with sevoflurane $(2.0 \%)$ or isoflurane $(1.5 \%)$ and nitrous oxide $(66 \%)$ in the control group.

\section{Data analysis}

Within each group, MAP and HR data were analyzed by one-way analysis of variance (ANOVA) for repeated measures with Bonferroni's/Dunn procedure. Comparisons among the three groups were made by one-way ANOVA, followed by Bonferroni's modification of the $t$ test. Sex was compared using Chi-square analysis. All analyses were performed using StatView 
TABLE Demographic Characteristics of the Three Groups

\begin{tabular}{llll}
\hline & $\begin{array}{l}\text { Control } \\
(n=15)\end{array}$ & $\begin{array}{l}\text { Thoracic } \\
(n=15)\end{array}$ & $\begin{array}{l}\text { Lumbar } \\
(n=15)\end{array}$ \\
\hline Age $(\mathrm{yr})$ & $58 \pm 16$ & $56 \pm 17$ & $52 \pm 11$ \\
Sex $(\mathrm{M} / \mathrm{F})$ & $8 / 7$ & $9 / 6$ & $6 / 9$ \\
Height $(\mathrm{cm})$ & $158 \pm 8$ & $160 \pm 9$ & $159 \pm 8$ \\
Weight $(\mathrm{kg})$ & $56 \pm 6$ & $58 \pm 6$ & $58 \pm 13$ \\
MAP $(\mathrm{mmHg})$ & $96 \pm 13$ & $94 \pm 14$ & $92 \pm 12$ \\
HR (bpm) & $78 \pm 11$ & $81 \pm 13$ & $85 \pm 14$ \\
\hline
\end{tabular}

Values are expressed as the mean $\pm S D$.

$\mathrm{MAP}=$ mean arterial pressure. $\mathrm{HR}=$ heart rate.

There were no differences among the three groups.

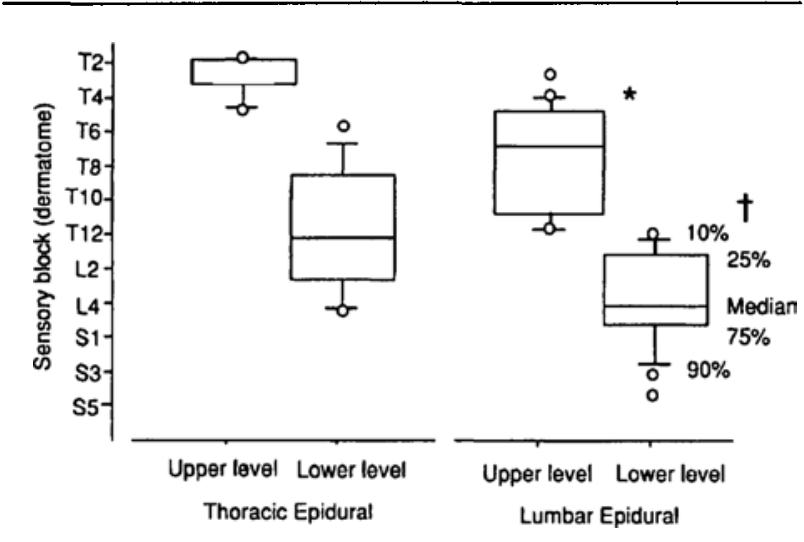

FIGURE 1 The upper and lower levels of thoracic and lumbar epidural block are compared by box plot. The median and range of blockade for each group are noted, as is \% of patients obtaining the denoted level of block. Open circles indicate out of 10 or $90 \%$ of patients.

* $P<0.05$ ) between the upper level of block achieved with thoracic ps lumbar epidural anaesthesia and between groups in the lower level of block.

(Abacus, Berkeley, CA), and values are expressed as the mean $\pm \mathrm{SD}$. A value of $P<0.05$ was considered statistically significant.

The extent of epidural block in the thoracic and lumbar groups was compared using the Mann Whitney $U$ test, and the values for the upper and lower levels of analgesic spread are presented as the median and range.

\section{Results}

There were no differences among study groups in the distribution of age, sex, height, weight, or baseline mean arterial pressure or heart rate values (Table). The magnitude and distribution of sensory block differed between the two epidural groups (Figure 1).

Following epidural anaesthesia, MAP decreased
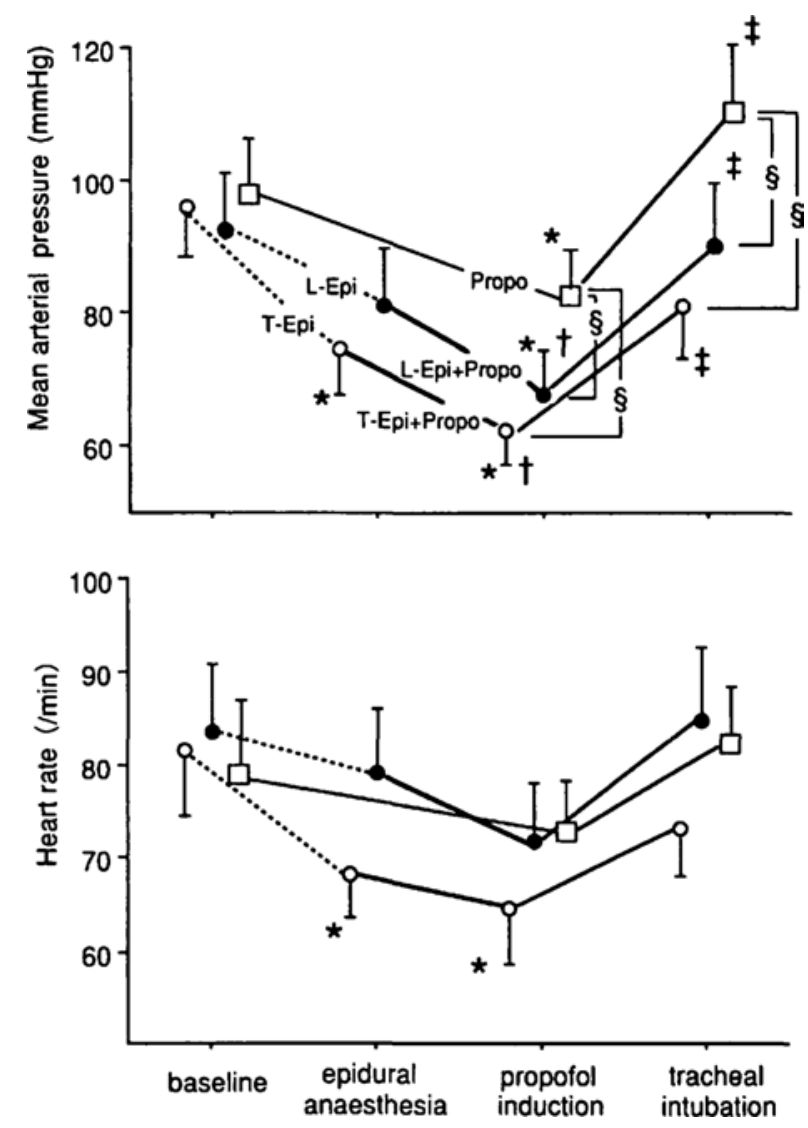

FIGURE 2 Comparative changes in mean arterial pressure (upper figure) and heart rate (lower figure) during propofol induction with or without epidural anaesthesia. The changes occurring with tracheal intubation are also provided. Dotted lines show the effects of thoracic or lumbar epidural anaesthesia. Heavy lines show the effects of propofol induction during thoracic or lumbar epidural anaesthesia. Open square = control group ; induced only with propofol, solid circle = lumbar group; given lumbar epidural anaesthesia before propofol induction, open circle = thoracic group; given thoracic epidural anaesthesia before propofol induction. Mean $\pm S D{ }^{*} P<0.05$ vs baseline, $+P<0.05$ vs epidural anaesthesia, $\ddagger P<0.05$ vs propofol induction, $\$ P<$ 0.05 vs propofol without epidural anaesthesia.

from $94 \pm 14$ to $75 \pm 11 \mathrm{mmHg}(P<0.0001)$ in the thoracic group, and from $92 \pm 12$ to $83 \pm 15 \mathrm{mmHg}$ in the lumbar group (Figure 2). Following propofol induction, MAP decreased further in the thoracic group to $63 \pm 9 \mathrm{mmHg}(P=0.0077)$ and to $67 \pm 10 \mathrm{mmHg}$ $(P=0.0076)$ in the lumbar group. The MAP following propofol induction was lower in the thoracic $(P<$ $0.0001)$ and lumbar $(P=0.0001)$ groups than in the control group given general anaesthesia alone. After tracheal intubation, MAP increased in all three study groups $(P<0.0001)$, but remained lower in the tho- 
racic $(P<0.0001)$ and lumbar $(P=0.0004)$ epidural groups. One patient each in the thoracic and lumbar epidural groups required ephedrine after tracheal intubation to counteract respective reductions in MAP to 49 and $47 \mathrm{mmHg}$.

Following epidural anaesthesia, HR decreased in the thoracic group from $81 \pm 13$ to $69 \pm 9$ beats per minute ( $P=0.0066)$, but remained unchanged in the lumbar group (Figure 2). Propofol produced no further decrease in $\mathrm{HR}(65 \pm 12$ beats per minute) in the thoracic group. There were no changes in HR in the lumbar epidural and control groups after propofol induction or tracheal intubation.

\section{Discussion}

Our findings indicate that the use of propofol for induction of general anaesthesia during epidural anaesthesia intensifies the hypotension introduced by the epidural technique. Propofol administration decreased MAP in the control group by $16 \%$ from baseline. Epidural anaesthesia alone decreased MAP in the thoracic and lumbar groups by $20 \%$ and $10 \%$, respectively, from baseline. Administration of propofol produced a total decrease in mean arterial pressure of $33 \%$ in the thoracic group and of $27 \%$ in the lumbar group. These results suggest that the haemodynamic effects of propofol are additive to those of epidural anaesthesia, and that the use of propofol as an induction agent during epidural anaesthesia may produce profound hypotension.

Before establishing epidural anaesthesia, we administered HES for volume loading to increase stroke volume and cardiac output in an effort to prevent severe hypotension before propofol injection. ${ }^{11,12}$ Nonetheless, mean arterial pressure and heart rate decreased in response to both thoracic and lumbar epidural anaesthesia and heart rate declined in response to thoracic epidural anaesthesia.

Our propofol induction technique is the same as that reported by others. We administered an induction dose of $2 \mathrm{mg} \cdot \mathrm{kg}^{-1}, 3,13,14$ followed by an infusion of 4 $\mathrm{mg} \cdot \mathrm{kg}^{-1} \cdot \mathrm{hr}^{-1} \cdot{ }^{15,16}$ Additionally, the speed of administration of the propofol injection was within the range $\left(2 \mathrm{mg} \cdot \mathrm{kg}^{-1}\right.$ over 5,20 , or $\left.60 \mathrm{sec}\right)$ reported to have no effect on $\mathrm{MAP}^{14}$ - our injection rate of $200 \mathrm{mg} \cdot \mathrm{min}^{-1}$ corresponded to a speed of approximately $30 \mathrm{sec}$.

Induction of general anaesthesia with a $2 \mathrm{mg} \cdot \mathrm{kg}^{-1}$ bolus dose of propofol has been reported to decrease systolic and diastolic blood pressures by $24 \%$ and $17 \%$, respectively, ${ }^{13}$ and to reduce mean arterial pressure by $1.0-20 \% .^{14}$ Consistent with these values, our general anaesthesia control group experienced a $16 \%$ reduction in mean arterial pressure during induction with the same dose of propofol. Epidural anaesthesia alone decreased mean arterial pressure in the thoracic and lumbar groups by 20 and $10 \%$, respectively. Subsequent administration of propofol for induction of anaesthesia decreased these values by an additional 13 and $17 \%$ from baseline, and 16 and 19\% from epidurally induced change. Thus, with or without epidural anaesthesia, the use of propofol decreased mean arterial pressure, indicating additive hypotensive effects for the epidural technique and propofol administration.

Epidural anaesthesia reduces arterial blood pressure by blocking sympathetic nerve activity. The additional reduction in MAP observed with propofol may be due to the direct effects of propofol on vascular tone and/or cardiac contractility. Supporting this possibility is the finding in patients undergoing coronary artery bypass graft surgery that induction with $1.5 \mathrm{mg} \cdot \mathrm{kg}^{-1}$ propofol iv, decreased systolic arterial pressure by $28 \%$ and diastolic pressure by $23 \%{ }^{17}$ In the present study, one patient each in the lumbar and thoracic epidural groups required ephedrine after tracheal intubation to treat a decrease in MAP $<50 \mathrm{mmHg}$ following administration of propofol. Both patients recovered immediately, with no further complications. However, this finding suggests that propofol in combination with epidural anaesthesia may produce an unpredictable, potentially profound, degree of hypotension in patients who have cardiac impairment and/or hypovolaemia.

Unlike midazolam, infusion of propofol for sedation has been associated with reduced heart rate. ${ }^{18}$ The difference between these agents may be due to the effects of propofol on the baroreflex response, ${ }^{19,20}$ which produce a lower heart rate despite decreased mean arterial pressure. In the present study, propofol produced no decrease in heart rate beyond that associated with thoracic epidural anaesthesia, with the exception of a slight decrease from baseline following tracheal intubation. These data suggest blockade of the cardiac sympathetic nerves as the aetiology of reduced heart rate in our patients, and minimal effect of propofol on heart rate during epidural anaesthesia.

In summary, the haemodynamic effect of propofol during epidural anaesthesia varies according to the parameter measured. Propofol has a reducing effect on mean arterial pressure, but no discernible effect on heart rate. We need further study that propofol may produce profound hypotension when administered in combination with epidural anaesthesia, particularly in patients at risk of cardiac fragility or hypovolaemia.

\section{References}

1 Taniguchi $M$, Kasaba T, Takasaki M. Epidural anesthesia enhances sympathetic nerve activity in the unanesthetized segments in cats. Anesth Analg 1997; 84: 391-7. 
2 Sellgren J, Pontén J, Wallin BG. Percutaneous recording of muscle nerve sympathetic activity during propofol, nitrous oxide, and isoflurane anesthesia in humans. Anesthesiology 1990; 73: 20-7.

3 Pagel PS, Warltier DC. Negative isotrophic effects of propofol as evaluated by the regional preload recruitable stroke work relationship in chronically instrumented dogs. Anesthesiology 1993; 78: 100-8.

4 Robinson BJ, Ebert T], O'Brien T7, Colinco MD, et al. Mechanisms whereby propofol mediates peripheral vasodilation in humans. Anesthesiology 1991; 86: 64-72.

5 Goodchild CS, Serrao JM. Cardiovascular effects of propofol in the anaesthetized dog. Br J Anaesth 1989; 63: 87-92.

6 Smith I, Monk TG, White PF, Ding $Y$. Propofol infusion during regional anesthesia: sedative, amnestic, and anxiolytic properties. Anesth Analg 1994; 79: 313-9.

7 Wilson E, David A, Mackenzie N, Grant IS. Sedation during spinal anaesthesia: comparison of propofol and midazolam. Br J Anaesth 1990; 64: 48-52.

8 Fanard L, Van Steenberge A, Demeire, van der Puyl F. Comparison between propofol and midazolam as sedative agents for surgery under regional anaesthesia. Anaesthesia 1988; 43(Suppl): 87-9.

9 Luchetti $M$, Palomba R, Sica G, Massa G, et al. Effectiveness and safety of combined epidural and general anesthesia for laparoscopic cholecystectomy. Reg Anesth $1996 ; 21: 465-9$.

10 Jessop E, Grounds RM, Morgan M, Lumley J. Comparison of infusions of propofol and methohexitone to provide light general anaesthesia during surgery with regional blockade. Br J Anaesth 1985; 57: 1173-7.

11 McCrae $A F$, Wildsmith $J A W$. Prevention and treatment of hypotension during central neural block. $\mathrm{Br} \mathrm{J}$ Anaesth 1993; 70: 672-80.

12 Lewis $M$, Thomas $P$, Wilkes $R G$. Hypotension during epidural analgesia for Caesarean section. Anaesthesia 1983; 38: 250-3.

13 Coates DP, Monk CR, Prys-Roberts C, Turtle $M$. Hemodynamic effects of infusions of the emulsion formulation of propofol during nitrous oxide anesthesia in humans. Anesth Analg 1987; 66: 64-70.

14 Rolly $G$, Versichelen $L$, Huyghe L, Mungroop. Effect of speed of injection on induction of anaesthesia using propofol. Br J Anaesth 1985; 57; 743-6.

15 Kirkpatrick T, Cockshott ID, Douglas EJ, Nimmo WE. Pharmacokinetics of propofol (diprivan) in elderly patients. Br J Anaesth 1988; 60: 146-50.

16 Gepts E, Camu F, Cockshott ID, Douglas EJ. Disposition of propofol administered as constant rate intravenous infusions in humans. Anesth Analg 1987; 66: 1256-63.

17 Vermeyen KM, Erpels FA, Janssen LA, Beeckman CP, et al. Propofol-fentanyl anaesthesia for coronary bypass surgery in patients with good left ventricular function. Br J Anaesth 1987; 59: 1115-20.

18 Roekaerts PMHJ, Huygen FJPM, de Lange S. Infusion of propofol versus midazolam for sedation in the intensive care unit following coronary artery surgery. J Cardiothorac Vasc Anesth 1993; 7: 142-7.

19 Cullen PM, Turtle M, Prys-Roberts $C$, Way WL, Dye J. Effect of propofol anesthesia on baroreflex activity in humans. Anesth Analg 1987; 66: 1115-20.

20 Ebert TJ, Muzi M, Berens R, Goff D, Kampine JP. Sympathetic responses to induction of anesthesia in humans with propofol of etomidate. Anesthesiology 1992; 76: 725-33. 